\title{
0 direito e o senso comum
}

\section{Candido Motta Filho}

\author{
"Je pense juridiquement" \\ Prcard - "Le droit pur"
}

\section{A produção do direito}

Quando, no começo dêste século, acentuavam os teóricos do direito, a existência de uma crise conceitual, - escrevia Jéan de lo Brête, n'um gracioso romance, que "le sens commun est le moins commun de tous les sens".

A afirmação, que se perdia na banalidade de um romance para moças, traduzia, contudo, um estado de espírito e o grave aspecto de um dos problemas fundamentais da vida.

A decomposição do senso comum correspondia, pelo seu singular valôr sociogênico, a uma desvitalização da força jurídica existente. De um lado, surgia a ameaça da anarquia social, com o reaparecimento visivel de uma guerra de todos contra todos. $\mathrm{E}$, com isso, um predominio do "não senso". De outro, a ameaça do despotismo, com implantações do poder absoluto de uma vontade. E, com isso, a preponderância do "contra-senso".

Apresenta-se assim o quadro social de nossos dias, quando, em verdade, o direito objetivado nas leis e na justa disciplinação dos interesses, fôra, sempre, em grande parte, alimentado pelo senso comum.

Entre os valores psicológicos e sociais da vida, o senso comum foi um dos que viveram por conta da natureza e das 
regras da experiência humana. " $O$ senso comum, - escreve M. L. LE RoY - contem, em estado confuso e informe, incontaveis residuos de todas as opiniões filosóficas, de todas as sentenças que tiveram certa voga" (1).

Serve a imagem, mostrando que o senso comum, pelo que recebe, pelo que oferece e pelo que acumula atravéz dos alcontecimentos, - trabalha constantemente icomo terreno de aluvião. $\mathrm{O}$ direito aflora daí como uma vegetação propricia e se torna a sua linguagem correta e precisa, ou como o define DurkheIm, - "o simbolo vesivel da solidariedade social" (2)

Quando Garofalo diz que "o crime é a violação do sentimento medio de piedade e probidade" - está, sem duvida, dizendo que o crime é uma aberração do senso comum (3).

DURKHEIM assinala admiravelmente essa interdependência entre o direito e o senso comum, quando estudou a solidariedade mecânica. Ele encontra, nas raizes das instituições juridicas, um conjunto de crenças e sentimentos comuns, que classifica como "l'ensemble des similitudes sociales" (4). O senso comum é a prova dessa coexistência continua que assegura o direito de todos contra a arbitrariedade de alguns. "Geralmente se compreende por senso comum, - ensina Joufrroy, um certo numero de principios e de noções evidentes por si mesmo onde todos os homens colocam os motivos de seus julgamentos e as regras de sua conduta". (5)

Podemos acrescentar: - si, para Joufrroy, o senso comum é uma filosofia anterior à filosofia propriamente dita, êle tambem é um direito anterior ao direito.

(1) Garrigou-Lagrange - Le sens commun, pg. 15.

(2) Durkheim - De la division du travail social, pg. 28.

(3) Garofalo - Criminologia.

(4) DuRkheim - Op. cit. pg. 47.

(5) Jouffroy - Du sens commun et de la philosophie. 
A pressão do senso comum se faz de tal sorte que as correntes doutrinarias do direito, dele não podem fugir. 0 professor João ArRuda, ao iniciar sua lição sobre a Escola Historica mostra como ela está fundada "na natureza humana, e nas faculdades de que esta é dotada".

$E$ acrescenta, com sua douta erudição, referindo-se a Savigny : - "nós não podemos impor a um povo uma lingua artificial, não podemos determinar que um povo tenha tais ou tais instituições politicas; e, do mesmo modo, as instituições juridicas não devem ser impostas: - elas são o resultado das formas naturais, da atividade do povo." (6)

Savigny, dando novos rumos às investigações juridicas, chama de novo a atenção para o estudo do senso comum. Apoiado na experiência histórica, ele explica a origem do direito e diz que é "na comum consciência do povo que vive o direito positivo". (7)

Essa maneira de ver, que não se desmereceu em nossos dias, antes se transformou à luz sociologia jurídica, não é entretanto uma descoberta da escola histórica; vem da distancia dos tempos, desde que o direito foi proclamado e reconhecido como indispensavel ao andamento dos povos cultos. Quando Ihering proclamou que o direito romano se tornou, a semelhança do cristianismo, um elemento de civilisação do mundo moderno, (8) estava convencido, pelos seus estudos, de que o povo romano, superiormente pratico, criara um sistema juridico de alcance universal, pelo seu apoio na realidade. Para o romano, desde o "jus singulare" até ao "ratio juris", - a função do direito seria, sempre, "uma função de realisar". Para isso, o direit'o surge da propria indole humana e traduz o senso comum, mesmo quando formulado pelos doutores. E daí a importância do

(6) João Arruda - Filosofia do Direito, 1.0 v. pg. 111.

(7) Savigny - Traité de Droit Romain, 1.0 v. pg. 14.

(8) Ihering - L'Esprit du droit romain, 1.0 v. pg. 31 
costume na elaboração do direito romano - "usus longo tempore unus est legum cenectur".

Convem assinalar, neste passo, que o direito natural romano, ao emoldurar-se com o pensamento estoico, satisfaz às necessidades praticas do genio romano. CrCERo, como advogado e como politico, traduziu, na sua eloquência, a maneira estoica de ver o direito, isto é, de vê-lo conforme à réta razão e à natureza. Mesmo o "jus gentium" era, para GAIo, - "o que a razão natural estabeleceu entre os homens". 10)

Para conter o artificio das formulas, emendar as disposições deshumanas e impedir o que hoje se denomina "um direito injusto", o romano apoiava-se na razão natu. ral, nessa "communis opinio", nesse senso comum da economia social romana.

Cicero escreveu, a proposito, "que a natureza deu a todos os homens a razão e, por conseguinte, o direito, que é a réta razão que manda e proibe." (11)

Colocado no quadro da filosofia etico-religiosa da vida romana, o direito natural vale por si mesmo e não demanda outras origens, outras explicações e esclarecimentos. Está na consciência de todos, e por isso, é anterior a organisação do Estado. No pensamento de Ulpiano, o direito é comum aos proprios animais.

$E$ quem percorre as varias doutrinas referentes ao direito natural até nossos dias, nelas encontra, na variedade conceitual desse direito, o senso comum, como um fato da natureza ou como uma decorrência da razão natural. Assim como, ainda no meio do seculo XIII, Graciano estabelece, em seu "Decretum" o principio de que a humanidade se rege pelo direito natural e do costume, - HoBBes, em posição diversa, concluiu não só pela existencia de um direito natural,

(9) Titio Livio, $X, 8$ v. 32.

(10) Instit. I, i, Dig. I, 1, 9.

(11) Craero - De Legibus, I, 10, 12. 
direito comum, a todos os homens, como do "apetitus societatiis". O poder que pode recair sobre um homem, ou sobre uma assembléia, decorre de uma compreensão comum". (12)

Do seculo XVII, em deante, depois de Descartes, Pascal e SpINosa, com o reaparecimento de grandes juristas, como Grotius e Bodin, a medida que se possibilitam maiores horizontes para o direito individual, mais se evidencia 0 senso comum, como senso social do individuo.

O homem é igual ao homem, quer na conciencia, quer na discordia, e, por ser assim, o direito que é uma arma de luta pela vida, decorre da mutua compreensão humana, como foi bem assinalada numa passagem ciceroneana: "natura enim juris explicando est nobis, aeque ab homines repetendo natura",(13). Na sensibilidade social está o reflexo da sensibilidade humana. Somos, no diz̈er de São Paulo, partes ou membros uns de outros.

Del Vecchro, neste mesmo campo de estudo, diz: "Os homens são partes e membros uns de outros, estão solidamente unidos, enquanto iguais e enquanto desiguais." (13)

Nas divergencias que decorrem da propria natureza humana, que produzem lutas e conflitos, o senso comum é reserva constante da sociabilidade e da individualidade, apelando para o contrato enquanto são iguais e, enquanto desiguais, apelando para a lei.

A densidade da vida moderna, complexa pelo individualismo e pelo liberalismo, encontrou, em seu amanhecer, em Rousseau, um genial interprete. $O$ seu contratualismo e a sua concepção de vontade geral, decorrem dessa identificação do humano em cada homem. Por isso, a vontade geral dá a impressão contraditoria, sendo e não sendo a vontade de todos. (14)

(12) Hoввеs - Leviathan, pg. 118.

(13) JORGE DEL VECchio - El concepto de la natureza y el principio del derecho, pg. IX v.

(14) Bigne de Villeneuve - Traité géneral de l'E'tat, 1.0 v. pg. 331 . 
E' que Rousseau, sentindo a realidade de atuadora do senso comum, distingue "a vontade geral", da "vontade comum", - il y a souvent bien de la différence entre la volonté de tous et la volonté général". (15)

Rousseau defende a tese de que "la volante général", o individuo a possui. Nesse instante está ele ao serviço do "l'intérêt commun" (16) e está assim estabelecendo a regra do "justo e do injusto" (17), tanto mais que "le premier et les plus grand intérêt public est toujours la justice. Tous veulent que les conditions soient éguales pour tous et la justice n'est que cette égalité (17).

Sem o senso comum, sem essa possibilidade de compreensão, a óbra de Rousseau não poderia ser construida. Sem o senso comum, como se concretizar, objetivamente, o aspecto normativo do direito?

E' o senso comum que facilita a transformação concentual do poder publico - de poder pela vontade divina, num poder comissario pela vontade geral.

Kant, que foi o teórico do Estado juridico, ledor e admirador de Rousseau, tinha a inteligência como o legislador de natureza. A emancipação da pessoa humana, na filosofia kanteana, se processa nessa natureza e se firma na base do senso comum. (18) O geral está no particular, e o particular no geral. O imperativo categorico realiza-se "sub specie aeterni". O direito, como principio universal, gira em torno do senso comum, para defende-lo e garanti-lo, dentro de um preceito obrigatorio. A faculdade de obrigar deriva do principio da natureza, da mutua obrigação entre os homens, dessa aluvião que se forma através do tempo.

A espantosa transformação dos nossos tempos, com o crescimento das populações urbanas, movediças e transitórias, - desarticulando assim o processo normal do senso

(15) Rousseau - Contrait social, L. II, C. II.

(16) Rousseau - Contrait social, L. I, C. VII.

(17) Lèttres de la Montagne.

(18) Durkheim - Op. cit. 
comum, vem facilitando aos observadores dos fatos sociais, o estudo mais acurado do problema. Já DuRKHeIm afirmava que podemos encontrar no direito todas as variedades essenciais da solidariedade social.

E' estudando o problema inter-psicológico, na sua obra "L'affirmation du Droif collectif", que Emmanuel Levy assinala os aspectos e os fundamentos das crenças coletivas, o papel preponderante do direito espontaneo, decorrente do que êle chama "notre nature, notre absulu." Êsse é o terreno, o vasto sub-solo do direito organizado, onde germina, como plantas nativas, o senso comum. E é, ao apreciar essa paisagem, que EHRI.cH, principalmente em sua "Contribution à la théorie des sources du droit" diz que o direito não passa de uma tecnica destinada a realizações praticas. Quem lê seu admiravel a "Grundlegung der Soziologie des Rechts," chega a conclusão de que o direito é, em grande parte, o senso comum tecnificado.

Com a renascença kanteana, com a filosofia dos valores, com Windelband, Ricker, Lask, Cohen, Nartop e principalmente, com Kelsen, Stammler e Radbruck, o problema se apresenta com novos dados e, consequentemente, com novos aspétos.

Kelsen, preocupado com a logica do "deve ser", reconhece e proclama que toda ordem juridica positiva pressupõe a obediência a um legislador originario e a norma como um esquema de interpretações.

O valor cultural do direito, sua validade como ciência do espirito, está em contraposição à ciência da natureza. (19)

Stammler mostra, em sua filosofia do direito, como o fenomeno juridico decorre de uma comum aspiração humana, historicamente condicionada. (20)

(19) KeLSEn - La teoria pura del derecho.

(20) Stammier - Tratado de Filosofia del derecho, pg. 10. 
Essa aspiração deriva de vocação para a sociabilidade, porque o direito é, para êle, "um modo especial de ordenar a convivencia humana".

Transferindo a formula do sentimento natural do direito, para o do conhecimento do direito, Srammler encontra, em vez de um sentimento comum, uma razão comum. (21)

Na procura da idéia do direito, RADBRuch ampara-se nessa realidade constante, através das mutações historicas, que é o senso comum. O direito é, para êle, como fenomeno cultural, "o conjunto dos dados da experiência que tem o sentido de realizar a idéia de Justiça".

$\mathrm{Na}$ sua critica ao direito natural, reconhece a permanencia da ideia do direito justo, "o qual se pode chamar direito natural."

- Neste fascinante mestre da filosofia do direito, como nos anteriores adeptos da restauração do racionalismo kanteano e da construção de uma peculiar e inconfundivel logica juridica, mais ainda se sobreleva a constancia do senso comum, na soma dos dados juridicos.

No fluxo de idéias e doutrinas, o direito se sustenta e se identifica como uma lingua geral dos povos; é, como diz o prof. Eugenio Sperantia, "um meio técnico do espírito." (23) Seja êle individualismo racionalista ou garantia social da personalidade humana (24), a verdade é que se socorre sempre do senso comum, quer na elaboração das leis, quer na aplicação das leis, quer na interpretação das leis. Aparecem-nos usos e costumes na voz dos doutores, na postulação das sentenças, nas dificuldades das lacunas e da obscuridade, no esclarecimento e definição dos principios gerais do direito e de equidade.

(21) Stammler - Tratado de Filosofia del derecho pg. 369.

(22) Radbruch - Filosofia do direito, pg. 26.

(23) E. Sperantia - Rev. Int. di Filosofia del Diritto, pg. 19, fasc. I, 1936.

(24) C. G. HAINES - The revival of naturae law concepts. 
II

\section{O formalismo jurídico e o senso comum}

Foi, principalmente, a partir da escola historica, interessada no problema da espontaneidade do direito, que se acentuou a campanha contra os perigos do formalismo juridicos e dos possiveis males da codificação. " $O$ direito costumeiro, assevera JHERING, tem sido, realmente, "l'enfant gaté" da chamada escola historica". (25)

A codificação, os processos do direito escrito, o formalismo judiciario, prejudicavam a formação natural do direito. Jhering cita, a propósito, o discurso de Stahl, em 11 de março de 1850, que afirma a capacidade destruidora da codificação, atingindo, em todos os casos, a espontaneidade de ciencia juridica.

0 protesto, iniciado assim em pleno romantismo, encontrou a resistencia da fé racionalista dominante, que deu ao direito construido um valor predominante. Á medida que se multiplicavam os problemas e se excedia a complexidade social, - a ciência juridica ia se deturpando " par les ravages de l'apriorisme et du pur formalisme". (26) O direito, amortecido nesse quadro, nessa esquematica preocupação do "homo juridicus", foi se tornando uma imposição destinada a suprir, como se fosse um aparelho ortopédico, a ausencia, cada vez mais notada, do senso comum.

Desde Napoleão que, de fato, o artificio vem substituindo o senso comum. (27) A lei seria, por si mesma, a segurança sobre os desatinos e violencias. "Toute la loi... mais rien que la loi...", divisa proclamada pelos interpretes do Codigo de Napoleão. Como o direito é uma construção

(26) JHERING - Op. cit. pg. 28, 2.0 vol.

(27) La Bigne de Villeneuve - La crise du Sens Comun das les Sciencies sociales, pg. 201. 
e nada mais do que uma construção, como diz DeL Vecchio, - "il diritto di natura diventa diritto di ragione." (28)

O fetichismo da lei cresce com o correr dos tempos. Caiu-se no formalismo puro, escreve Villenueve. E acrescenta: - "SaIeilles já o verificava em sua "Introduction à l'étude du Code civil allemand." O perigo dos codigos escrevera ele - está na substituição da ciência pela exegese, no entrave do progresso pelo abuso do formalismo e da casuistica e de estabelecer uma separação artificial e funesta, muitas vezes contraditória, entre o direito e os costumes, entre a lei e a equidade, entre os textos que exprimem o direito e as necessidades novas creadas." (29)

Maxime Leroy (30), estuda essa obcessão pelo formalismo legal, desde a Revolução Francesa ("Nul n'est humme de bien, s'il n'est franchement est religieusement observateur des lois". 5 const. - 1791-21-8), passando pelos legistas do Bonapartismo ("La observation du Code civil, diz Grenier, devencera la morale universelle) até nossos dias.

$\mathrm{Ha}$, com o crescer das dificuldades sociais, um verdadeiro furor de legislar. A vida transforma-se a olhos vistos, os interesses se multiplicam, as necessidades se acumulam, acentuam-se as diferenças sociais e se aviva a consciencia dessa diferença. E os parlamentos são as maquinas de fabricar leis por atacado, a fim de conter essa superprodução de dificuldades. Até que, em 1936, quando a crise alcançava o seu zenith, Georges Ripert escreve: "Nosso século vê, todos os dias, o milagre da multiplicação das leis. Assemelha-se ao milagre do evangelho" (31).

A multiplicação das leis, dos decretos-leis, dos regulamentos e avisos, foi distanciando a legislação da realidade.

(28) Del Veccho - Lezioni di Filosofia del diritto, pg. 90.

(29) M. DE La Bigne de Villeneuve - Op. cit. pg. 86.

(30) M. LEROX - La loi, pgs. 25 e sgs.

(31) S. RIPERT - Le régime democratique et le droit-civit moderne, pg. 27. 
A ignorancia da lei, com isso, se torna proverbial. VilleNEUVE não trepidou em afirmar que o principio - "ninguem pode alegar a ignorância da lei — se tornou inaplicavel e ridiculo" (32).

Nessa confusão percebe-se a ausencia do senso comum, mesmo porque não ha maior prova da ausencia do senso comum do que essa multiplicação das leis. $O$ direito fugia delas, como elas fugiram da realidade. A reação começou, porém, com os estudos sociais, com as acusações de SaInt Simon e com as ponderações de Comre. Foi acolhida por alguns juristas corajosos, como Lambert e Morin, Saleilles e principalmente GéNY. E o consagrado mestre de Nancy que procura, em obra definitiva, demonstrar como o fetichismo da lei, significa a propria esterilidade da lei. É ele que marcha corajosamente para os caminhos esquecidos do senso comum, quando fala na "livre indagação cientifica" e distingue o construido do não construido. GÉNY mostra como a lei é o meio tecnico mais perfeito e mais comodo para a verificação dos dados primarios do direito (33). Porque, para ele, o direito natural ressurge, através de dados reais, historicos, racionais e ideais. Não é um privilegio do jurista, mas da vida humana. "La loi, diz ele, n'est qu'une opinion émise sur les données premières du droit".

Como o direito visa no quotidiano, a justiça, de certo modo, representa um equilibrio no jogo dos interesses, (Inering). E precisa ser, além de uma vocação comum a todo homem, - "un instrumento di prima necessità" (34). E até no seu aspecto de luta, uma forma de compreensão humana a serviço do homem e da comunidade.

A lei, no entanto, distanciada dos acontecimentos, dificulta o direito. Este não se expressa, numa luta. A luta

(32) Villeneuve - Op. cit. pg. 86. positif.

(33) GeNy - Méthode d'interprétation et sources du droit'

(34) F. Garnelutti - Discorsi in torno al diritto, pg. 3. 
se perde no ar, na divulgação dos -textos, no pedantismo das formulas, no obscurantismo das regras, na contradição volumosa das organisações judiciarias. Enquanto o jurista insiste em ficar no mundo da lua, lembra DABIN a diferença que existe no contrato de compra e venda para um jurista e para um homem de negocios. (35). 0 jurista que olha o direito, não deve perder de vista, de modo algum, o homem de negocio. (Scire leges non est verba earum tenere sed vim ac potestatem). E é por perde-lo de vista que Carnelutti escreve, com um certo sarcasmo, que os automoveis que saem das fabricas são muito mais modernos e perfeitos, do que as leis construidas nas oficinas legislativas" (36).

Não deixamos, por isso tudo, de vêr com certo conforto e simpatia, o que escreve Carlos Cassio, pensador novo na filosofia juridica argentina, a proposito do que ele chama - "teoria ecológica del derecho": "o objeto do conhecimento pelos juristas, não são as normas, senão a conduta humana, enfocada de um certo angulo particular" (37).

O Codigo Civil dispõe, no art. $3^{\circ}$, que a lei não prejudicará, em caso algum, o direito adquirido, o ato juridico perfeito ou a cousa julgada. E no seu $\S 20$ diz que "reputa-se ato juridico perfeito o já consumado, segundo a lei vigente, ao tempo em que se efetuou".

Mas, dentro desse labirinto legal de nossos dias, onde, repetindo uma banalidade, vemos numa lei modificada varias vezes, o direito deixa de ser, não raro, uma garantia, se não o socorre o conjunto de elementos que o formam e que se esclarece na decisão judiciaria, naquela "politique juridique des tribunaux" a que se refere LAMBERT.

A luta contra o fetichismo da lei ou contra a lei como unica solução do direito, só se pode fazer pelo reconheci-

(35) J. DABIN - La tecnique de l'élaboration du droit positif, pg. 117.

(36) Carnelutti - Op. cit., pg. 177. 
mento do direito vivo e espontaneo, pelo reconhecimento da intuição da verdade juridica que reside nuclearmente no senso comum.

\section{III}

\section{0 aspecto sociológico do senso comum}

Dizendo que o direito é um interesse protegido pela lei, JHERING colocava o problema juridico no plano social. Para ser a condição da existencia moral da pessoa, ele precisava respirar no mundo das competições, que é o mundo dos valores sociais. E que o homem, para JHERING, defendendo o seu direito pessoal, luta pela totalidade juridica ou pelo direito em si (32).

Assim, a luta pelo direito decorre da Iuta pelo senso comum, que é, no dizer de Bonrs, - "a filosofia do instinto".

A sociedade, no seu trabalho oculto ou ostensivo, cria um sistema de vida que a define e do qual deriva "o querer com os outros e o querer para os outros". Assim a ação individual leva sempre, consigo, um certo conteúdn social (33). E nesse momento que se pode dizer, com DeL Vecchio que "o direito de um povo - jus in civitate positum - é a expressão particular da exigencia universal da natureza humana" (34).

A inter-ação social, o influxo reciproco dos membros de uma sociedade não se processa num cáos, mas, ao contrario, apresenta-se, como na imagem de Simmex, como "um cosmo inteligivel" (34). A sociedade sente o individuo, o individuo sente a sociedade, o desconexo dos fatos disciplina-se pelas idéias, e estas, desse modo, se apresentam como "valores" e não como "existencia. Daí o valor existencial

(38) JHERING - A luta pelo direito.

(39) G. DEL Vecchio - Riforma del Codice civile.

(40) Simmel - Grundfragen der Soziologie. 
do senso comum, trabalhando, como um pacificador no choque natural das forças em antagonismo, na formula de Von WIESE, como "o conjunto de experiencias adquiridas, (41).

A sociabilidade, pelo senso comum, segrega os deveres jurídicos. Em sua "Sociologie juridique", George Gurvitch - distinguindo a sociabilidade espontanea da sociabilidade organizada, à semelhança da distinção de TonNIE, entre sociedade e comunidade (42) mostra que, toda a forma de sociabilidade ativa, é produto de um fato normativo, que se objetiva no direito espontaneo ou no direito organizado. $\mathrm{E}$ todas as diferenciações juridicas, sejam elas quais forem, dos quadros individuais, federalisados ou confederalisados, emanam sempre da mesma concepção ou realidade - que se define como o direito. Nelas, seja em torno de um contrato de compra e venda ou num contrato coletivo do trabalho, estão os mesmos elementos que compõem o direito como tal. Nelas deve atuar a influencia organica do senso comum (3).

No que se descobre atualmente, pelos atuais estudiosos da tipologia juridica, - seja ele um MAx WEBER ou seja ele um Karl Mannheim, - é essa luta do direito para livrar-se da parasitagem do artificialismo juridico que procura destrui-lo, como uma das expressões da desordem dos nossos dias. E, nessa luta pela purificação do direito, em que se vê a solução da crise social contemporanea, haverá, por certo, o necessario apelo ao senso comum, sinal visivel de todas as sociedades espontaneas e saudaveis. Porque para as sociedades exaustas, entregues de corpo e alma aos jogos de espirito, fazem sucesso as grandes negações e os grandes negadores, como Renan, que escreveu, um dia, que "tudo é f́cundo, excepto o bom senso".

(41) VoN WIESE - Wirstschaft und Recht der Gegennvant.

(42) G. Gunvitch - pg. 146.

(43) M. WEBER - Economia y sociedad. 